\title{
EIF2 Signaling
}

Overlay: Observatio
Extracellular space
Cyloplasm

Phosphorylation of elf2a by upstream
inhibits translation initiation
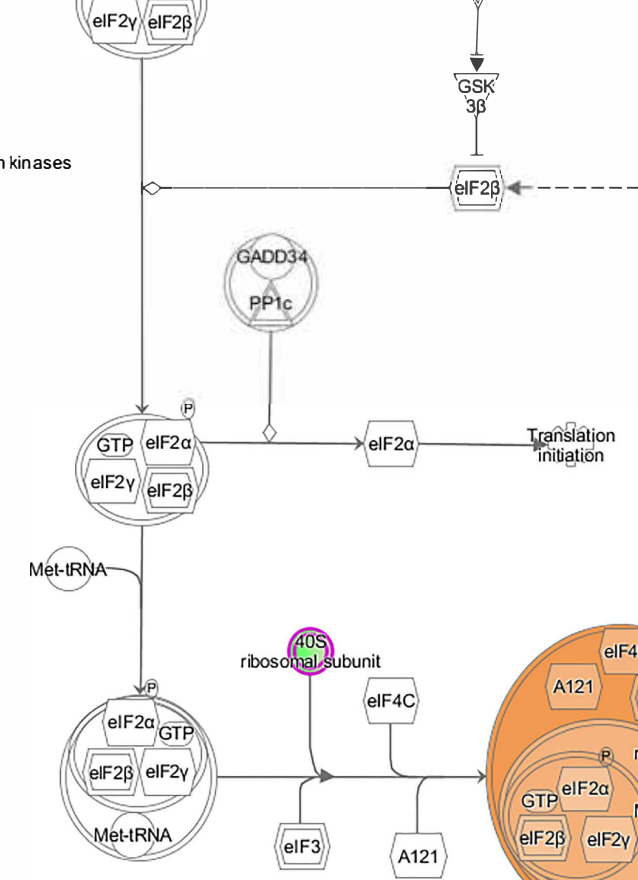

Transiation

elF2a GDP

elF2V elF2B

ER

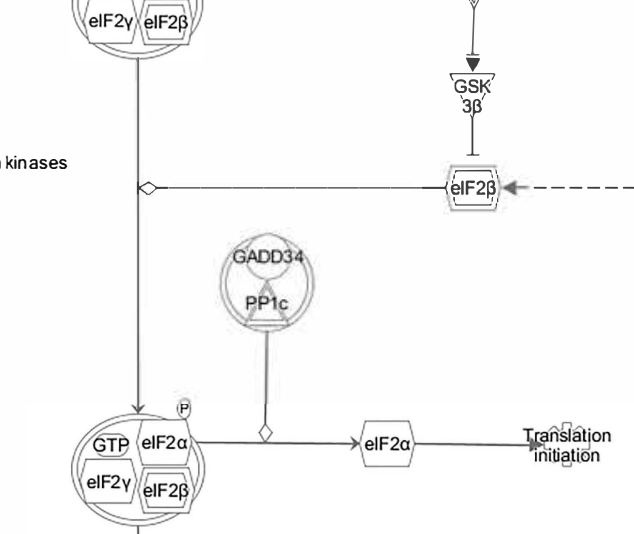

Met-tRNA-
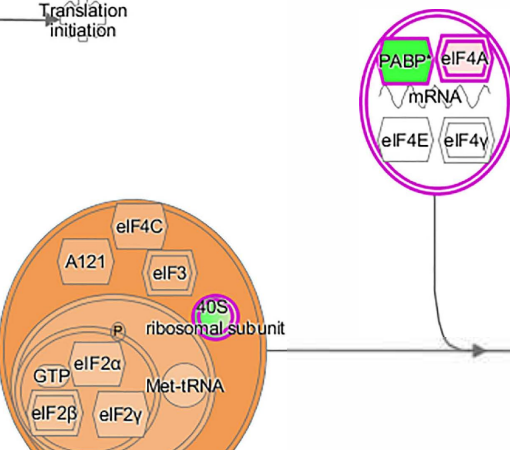

$\underset{\substack{\text { 60s } \\ \text { subunit }}}{\text { bosmal }}$

Prediction Legend-

more confidence less

Predicted activation

Predicted Relationships

- Leads to activation

Findings inconsistent

with state of downstream

molecule

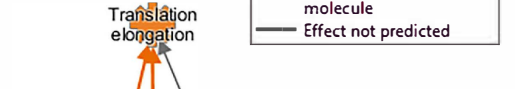

\section{LPS treatment}




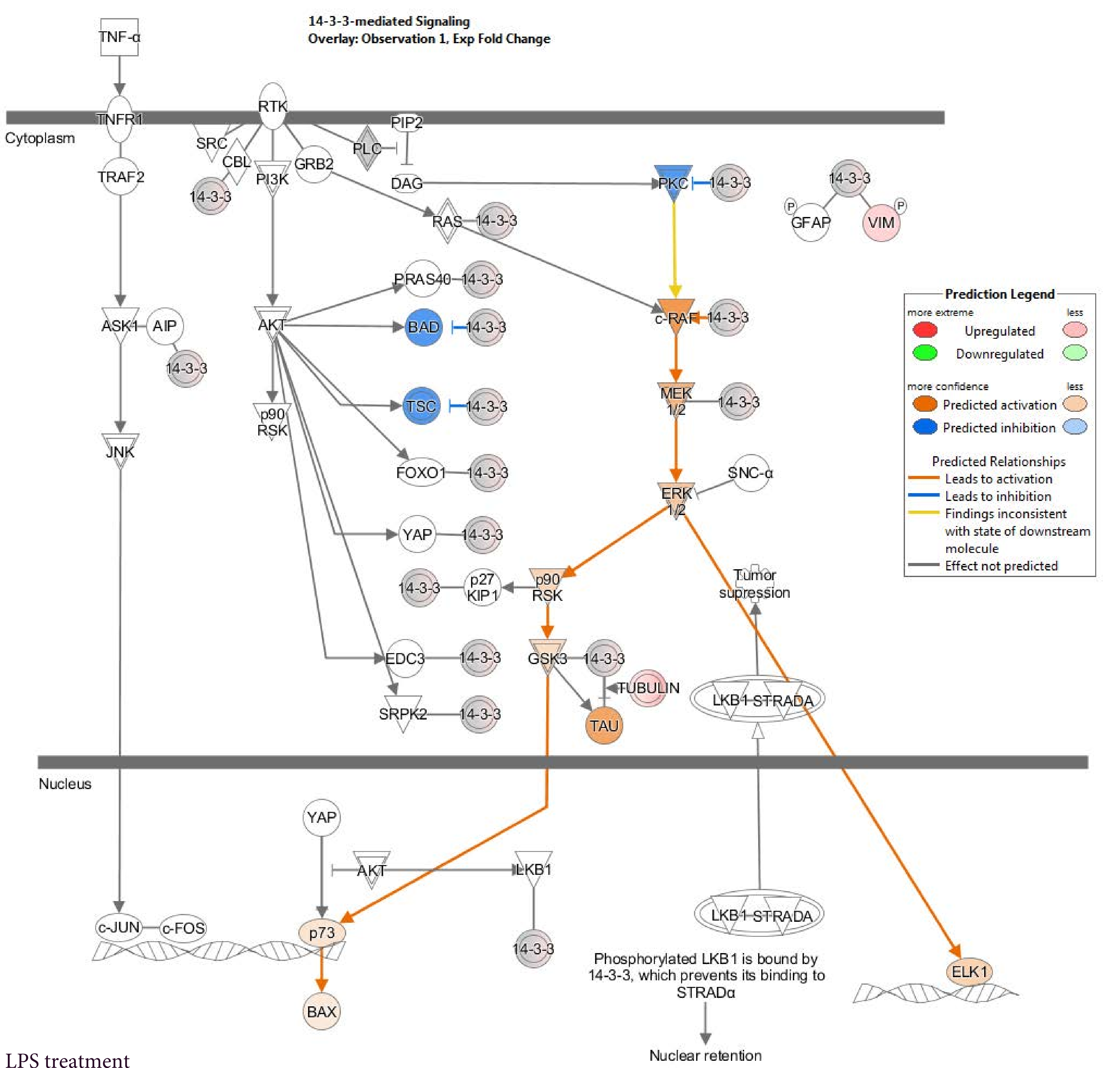




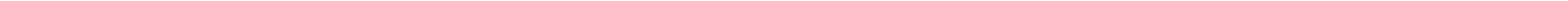


Extracellular space
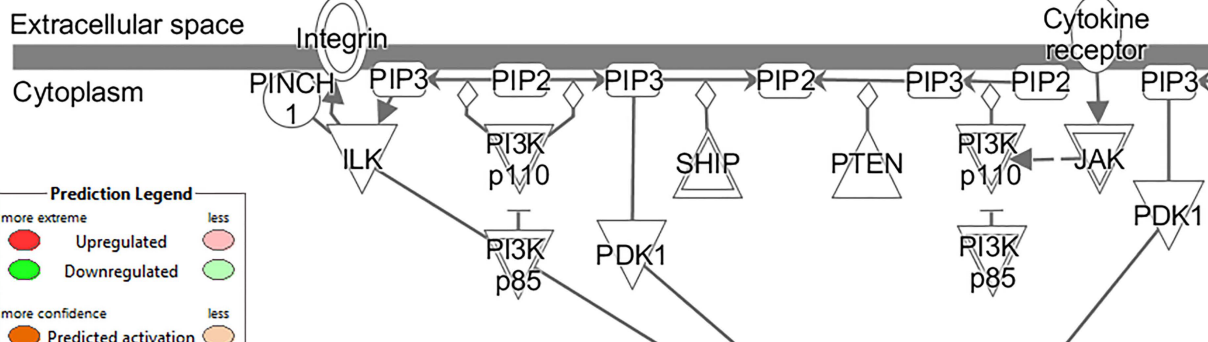

RTK RTK

Cytoplasm

.

molecule

\begin{tabular}{|c|} 
Downregulated \\
Urediction Legend \\
Unre extreme
\end{tabular}
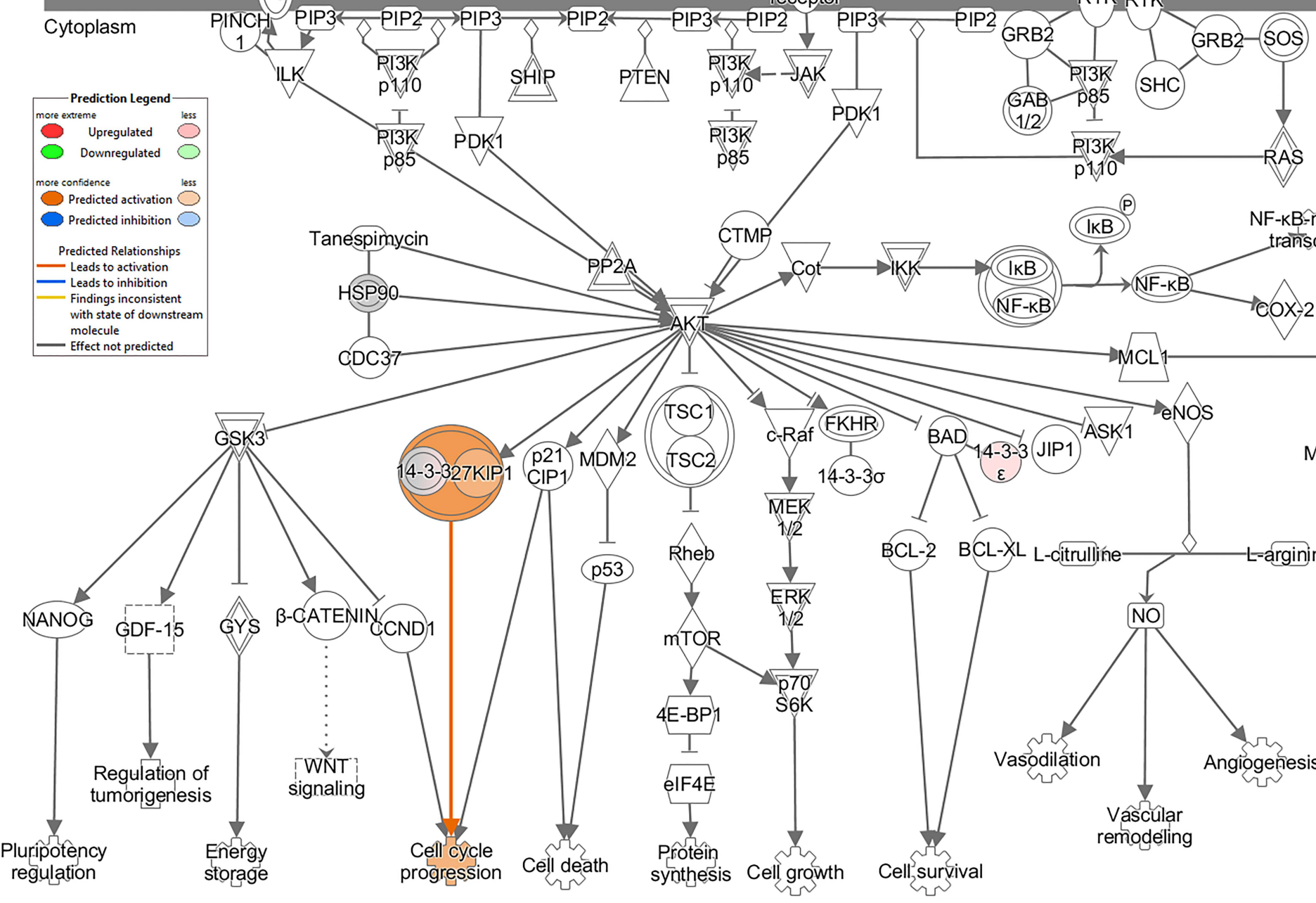



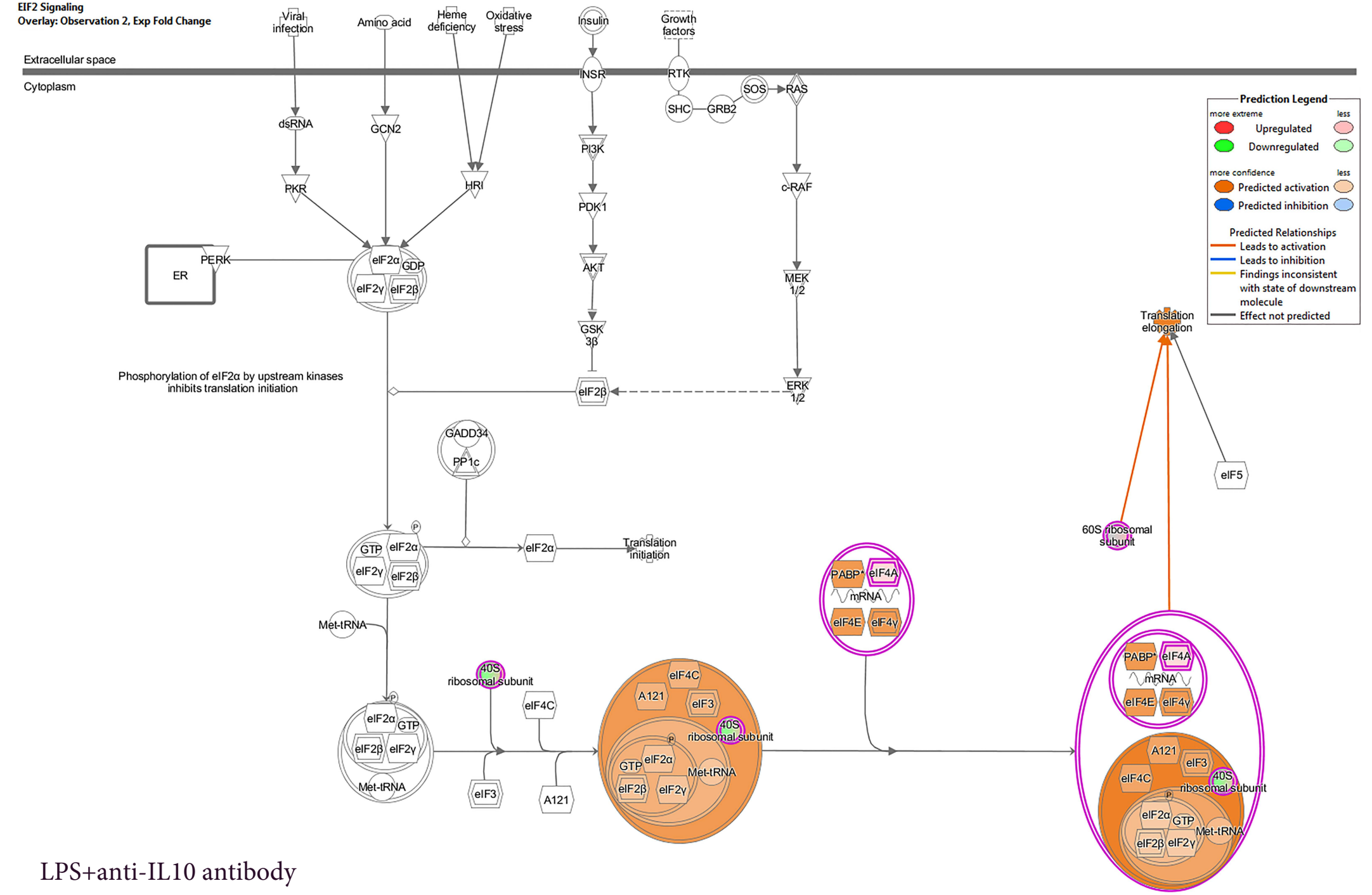





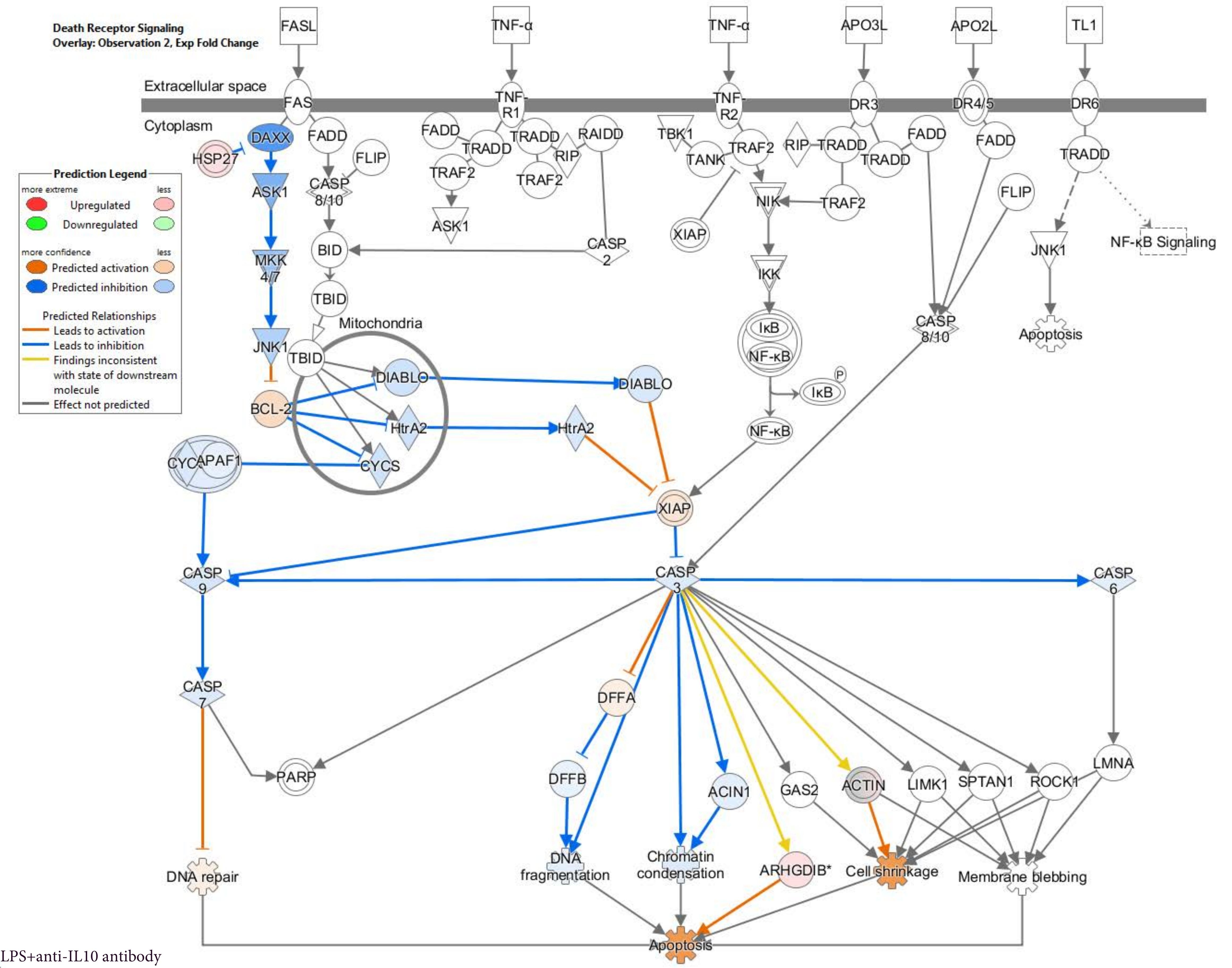




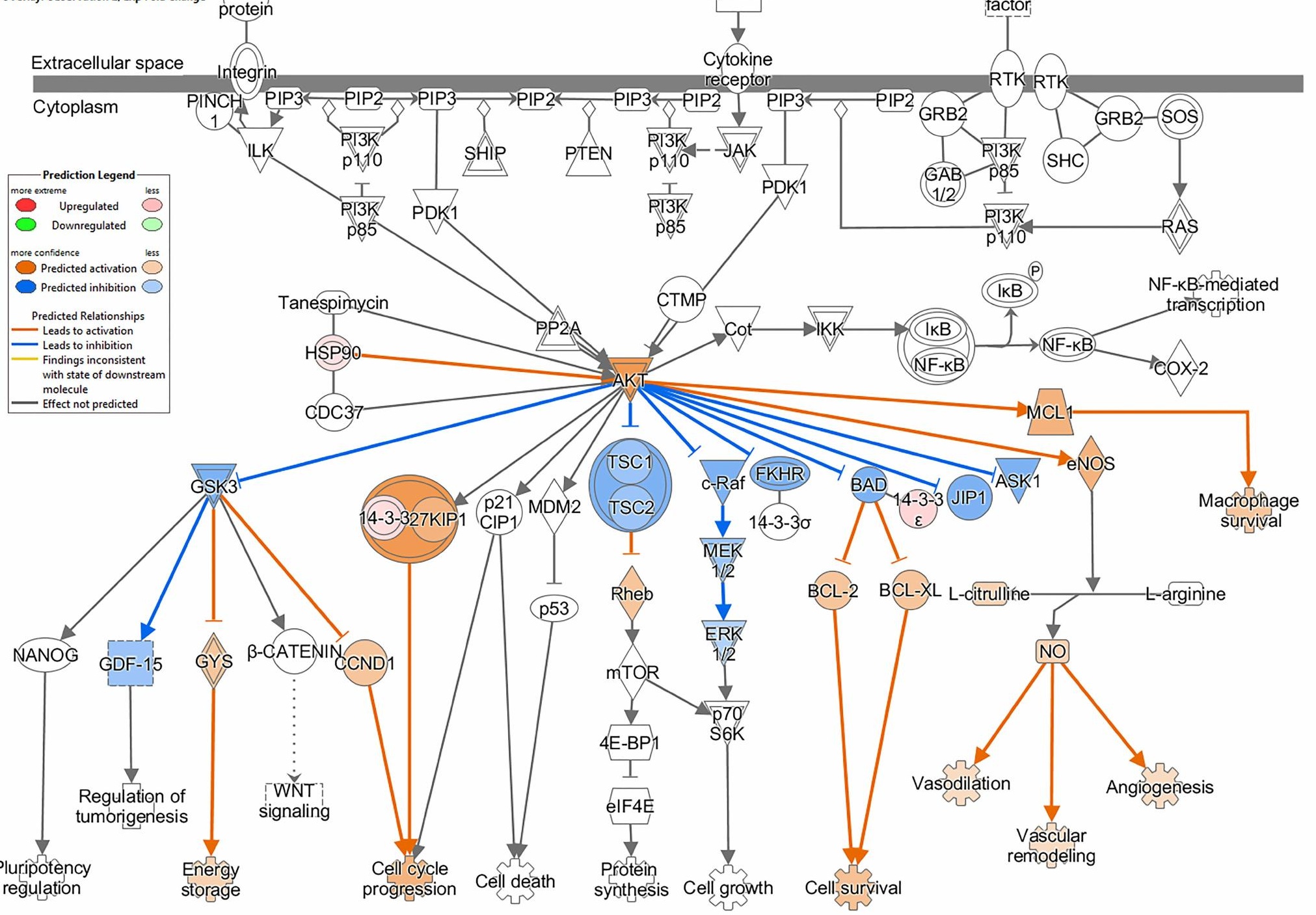




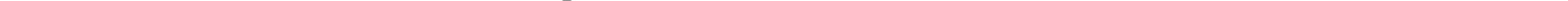




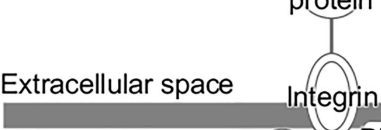

Cytoplasm
Prediction Legend
Upregulated
Downregulated
Predicted Relations
Predicted activation
Preads to activation
Leads to inhibition
Lindings inconsistent
with state of downstream
molecule

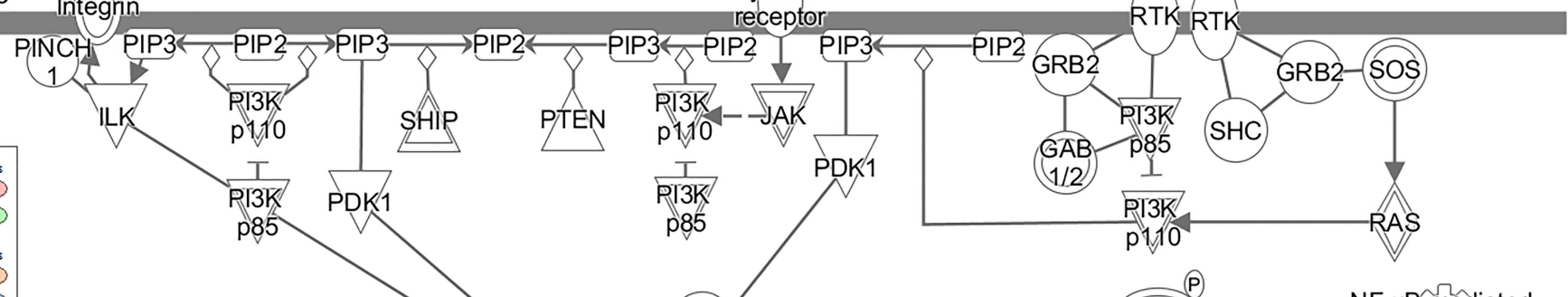

receptor

RTK RTK

- Effect not predicted
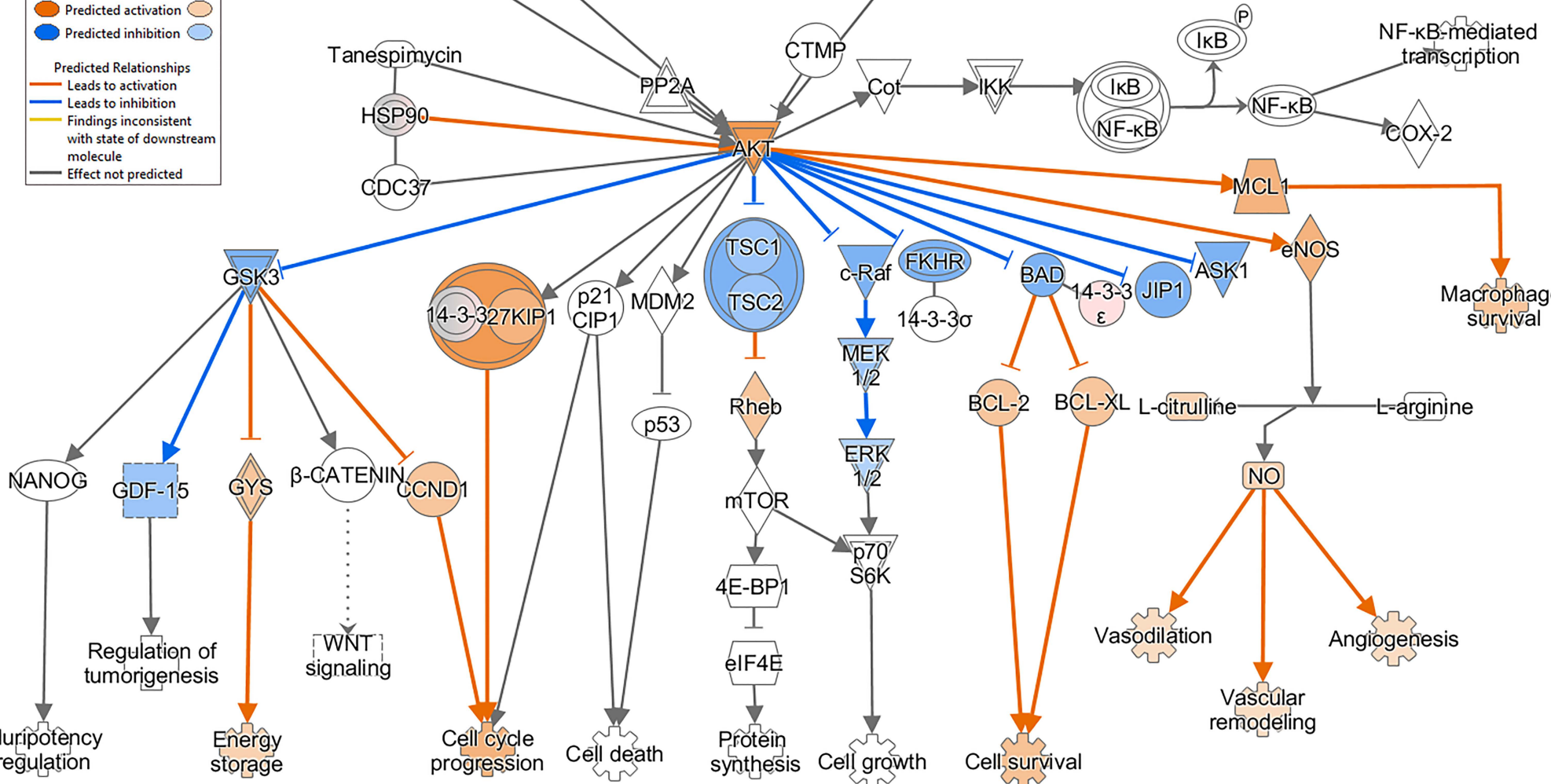

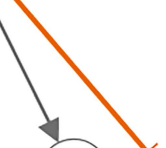

B-CATENIN CCND1

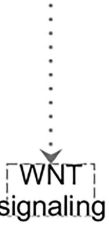
signaling
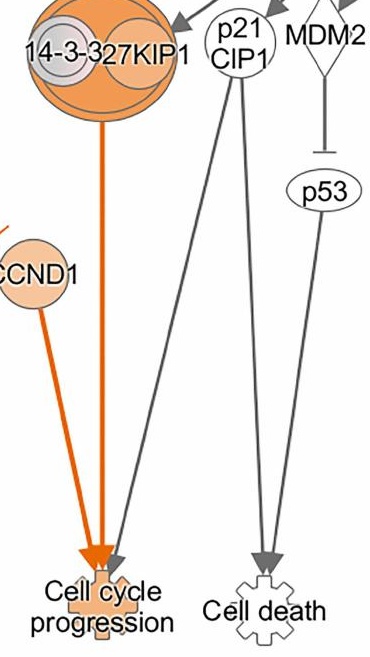

1
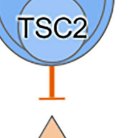

C-Raf FKHR $\frac{1}{\mathrm{MEK}} 14-3-3 \sigma$

Rheb

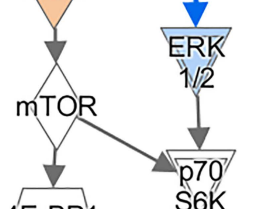
E-BP 1 S6K $\perp$ Protein synthesis Cell growth
Macrophage sưrvival 